\title{
Effect of Topical Steroid Treatment for Concealed Penis: Is It Managed Conservatively?
}

\author{
Katsuya Aoki*, Shinji Fukui, Maho Takenaga, Maikito Miyake, Takeshi Inoue, Satoshi Anai, \\ Kazumasa Torimoto, Nobumichi Tanaka, Kiyohide Fujimoto \\ Department of Urology, Nara Medical University, Nara, Japan \\ Email: ${ }^{*}$ aokik@naramed-u.ac.jp
}

Received 15 May 2014; revised 10 June 2014; accepted 18 June 2014

Copyright (C) 2014 by authors and Scientific Research Publishing Inc. This work is licensed under the Creative Commons Attribution International License (CC BY). http://creativecommons.org/licenses/by/4.0/

\section{(c) (i) Open Access}

\begin{abstract}
Purpose: Phimosis can be treated using topical steroid treatment effectively. Meanwhile, concealed penis has been required surgical correction because it was considered stubborn to conservative treatment. But there were few reports of conservative treatment using topical steroid treatment for concealed penis. The aim of the present study was to evaluate the effects of topical steroid treatment for concealed penis. Materials and Methods: From December 2006 to December 2011, 30 patients (mean age 9.3 years) with concealed penis were treated with topical $0.12 \%$ bethamethasone valerate cream. Patients or their parents continued to retract the prepuce gently without causing pain and to apply a topical $0.12 \%$ bethamethasone valerate cream to the prepuce twice daily for 6 weeks. When topical steroid treatment was ineffective, patients were surgically corrected. Results: The success rate of topical steroid treatment was low (10\%). 27 of 30 patients required surgical repair. No patients showed complications associated with topical steroid or surgical intervention. Conclusions: Concealed penis is highly resistant to topical steroid treatment and should be corrected surgically.
\end{abstract}

\section{Keywords}

Concealed Penis, Steroid, Indication of Surgery

\section{Introduction}

Phimosis is a physiological condition in infants. In most cases the prepuce detaches spontaneously from the

\footnotetext{
${ }^{*}$ Corresponding author.
}

How to cite this paper: Aoki, K., Fukui, S., Takenaga, M., Miyake, M., Inoue, T., Anai, S., Torimoto, K., Tanaka, N. and Fujimoto, K. (2014) Effect of Topical Steroid Treatment for Concealed Penis: Is It Managed Conservatively? Open Journal of Urology, 4, 82-86. http://dx.doi.org/10.4236/oju.2014.46014 
glans and becomes retractable over the glans by 3 years of age [1]. Persistent phimosis predisposes to inflammatory and infectious diseases, for example balanoposthitis, balanitis, HIV and HPV [2] [3]. Topical steroids have been advocated as a safe and economical alternative to surgical intervention with success rates of $65 \%$ to 95\% [4]-[6]. Meanwhile, concealed penis required to be corrected surgically, because it was stubborn spontaneously due to a severe prepucial phimotic ring, deficient penile shaft skin and dysgenesis of dartos bands [7]-[9]. Though several surgical procedures for concealed penis repair were reported, they are at risk of developing complications including secondary concealment and ventral edema. In the past there were only 2 reports about topical steroid treatment for concealed penis with success rates of $0 \%$ to $50 \%$ [10] [11]. In this study, we evaluated the possibility of conservative treatment for concealed penis.

\section{Materials and Methods}

A concealed penis is defined as a phallus of normal size buried in prepubic tissue (buried penis), enclosed in scrotal tissue (webbed penis), or trapped by scar tissue after penile surgery (trapped penis) according to Maizel's classification [12]. In this study, all the cases of concealed penis were applied to buried penis or webbed penis. Patients with prior systemic or topical use of steroid and those with balanitis xerotica obliterans were not indicated to topical steroids treatment.

From December 2006 through December 2011, 30 patients with concealed penis were evaluatedand treated with topical $0.12 \%$ bethamethasone valerate cream by a single pediatric urologist (KA). Patients and their parents were instructed to retract the prepuce gently without causing pain and to apply a topical $0.12 \%$ bethamethasone valerate cream to the prepuce twice daily for 6 weeks. Full retraction of the prepuce and partial exposure of the glans due to adhesion of the inner prepuce to the glans without a narrow ring were considered successful. When topical steroid treatment was unsuccessful, patients underwent concealed penile repair by Sugita's procedure [8].

The institutional reviewer board approved this clinical study. Informed consent was obtained from all patients or parents of underage patients after fully giving explanation of the conservative treatment and surgical intervention.

\section{Results}

A mean age was 9.3 years ranging from 4 to 26 . Two adult patients were included. All the patients completed topical steroid treatment. A success rate of topical steroid treatment was low (10\%, 3/30) (Figure 1). 27 of 30 patients received surgical repair by Sugita's procedure. The mean follow-up periods were 29 months (range: 16 to 40). Patients treated with topical steroid showed no adverse events through the treatment period, and those who needed surgical intervention also had no postoperative complications without temporary lymph edema (Figure 2). All of patients and their parents were satisfied with the present therapeutic outcomes.
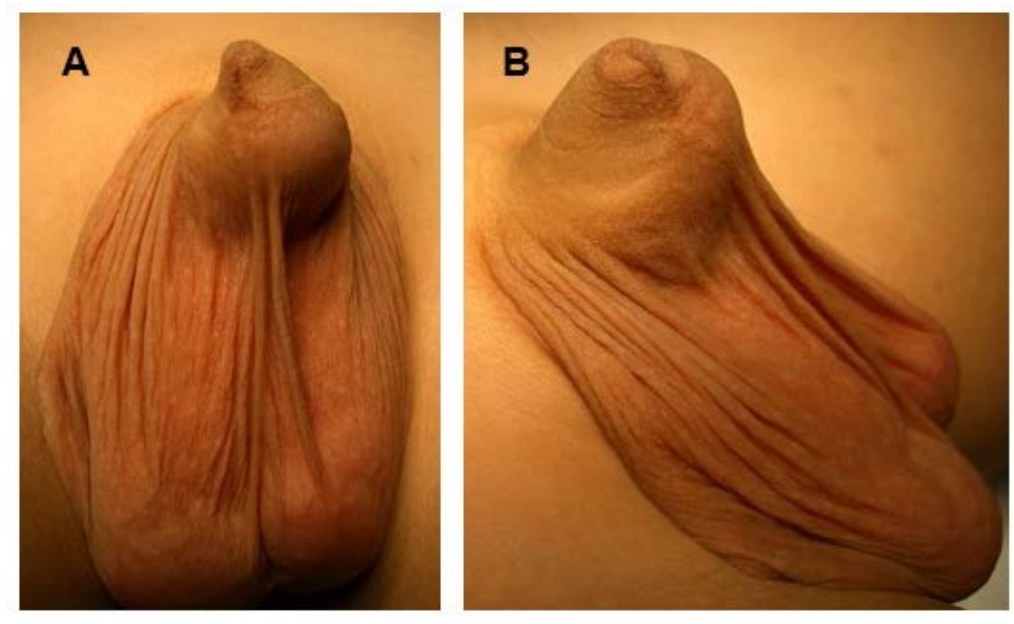

Figure 1. Pictures of a 4-year-old patient with success of topical steroid treatment for concealed penis taken. (A) before treatment; (B) after treatment. 


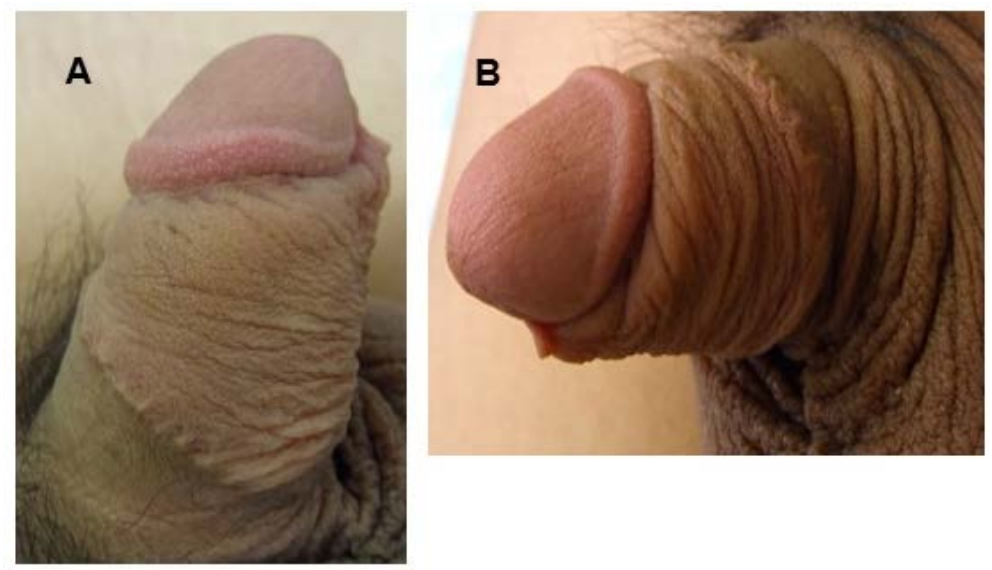

Figure 2. Pictures of another 12-year-old patient with concealed penis taken after surgery. (A) frontal view; (B) lateral view: showing the penis successfully covered with inner prepuce.

\section{Discussion}

The penile anomaly consisting of a phallus of normal girth and short length covered mostly by a prepuce was originally described by Crawford in 1977 [13]. He called the anomaly a buried penis. In his report, which consisted of 6 cases observed, he outlined a classification system that included concealed penis, partial and complete forms of buried penis, and penoscrotal webs. Maizels et al. reclassified concealed penis into buried penis (buried in prepubic tissue), webbed penis (enclosed in scrotal tissue), trapped penis (trapped by scar tissue after penile surgery) and micropenis [12]. In this study, all the cases of concealed penis were applied to buried penis or webbed penis. Meanwhile, Casale et al. categorized concealed penis into 3 subtypes, including congenital concealed penis, concealed penis due to scarring from previous surgery and complex cases of excessive obesity [14]. In this study all cases were categorized as congenital concealed penis.

There were few report about the natural history of concealed penis. Radhakrishnan et al. reported that of 51 cases of concealed penis managed conservatively 29 resolved spontaneously by age 3 years, 8 were still being observed, 9 were lost to follow up and 5 underwent surgery elsewhere [7]. The question by Frank [15] in an editorial comment on 3 studies describing the management of the buried penis, which is probably categorized as congenital concealed penis in Casale's report, is provocative: "Why do our adult urologist colleagues not see this condition in the older patient?" He surmised that the condition corrects itself at puberty. In our study, there were two adult patients who were bothered by dribbling after voiding, soreness during the sexual intercourse and social embarrassment among peers. It is known that concealed penis does not always improve spontaneously at puberty. Gillett et al. reported that waiting for pubertal hormonal changes to correct this problem was usually unsatisfactory to patients and their parents [16]. We think that children age 3 years and older should be treated if concealment causes difficulty in keeping proper hygiene, bothersome at voiding and psychological problems.

Topical steroids have been advocated as a safe and economical alternative to surgical intervention, with success rates of $65 \%$ to $95 \%$ in pediatric phimosis [4]-[6]. On the other hand, only 2 previous reports showed the results of topical steroid treatment for concealed penis with success rates of $0 \%$ to $50 \%$. Chu et al. also reported that 5 of 10 patients (50\%) with buried penis patients indicated significant improvement after being treated with topical steroid treatment [10]. Webster et al. reported that 2 patients with buried penis failed in topical steroid treatment and required surgery [11]. In our patients, only 2 patients (10\%) with concealed penis became healed to retract the prepuce after topical steroid treatment. Effect of topical steroid treatment seems to vary among a few reports including ours. The variation of success rates between these reports may be due to the differences of patient age distribution. It is assumed that our patients showed a low efficacy rate of topical steroid treatment since they were older than those in Chu's study.

Zampieri et al. described that there were 2 possible mechanisms by which steroid cream may help resolve phimosis [17]. One is an anti-inflammatory and immunosuppressive effect. Corticosteroids not only inhibit the early phenomenon of inflammation but also its later manifestations. The other is skin thinning. Steroids inhibit the dermal synthesis of glycosaminoglycans by fibroblasts, resulting in the loss of ground substance subsequent 
to decreased binding of tissue fluid to the hyaluronic acid. They have an active role in the inhibition of collagen synthesis and have antiproliferative effects on the epidermis. There is a relative large discrepancy in an effect of topical steroid treatment between physiological phimosis and concealed penis. This discrepancy is likely due to the difference of etiologies; namely, a severe prepucial phimotic ring, deficient penile shaft skin, and dysgenesis of dartos bands [7]-[9]. So we think that a first-line therapy by topical steroid may not be applied to concealed penis and surgery should be selected.

Repair surgery of concealed penis had 2 important procedure points as follows; one is dissection of phimotic ring and dysgenetic dartos fibers and the other is covering with reallocated inner prepuce for a paucity of penile shaft skin. In our series of patients we performed a Sugita's procedure which is simple and has natural suture lines for concealed penis repair [8]. They reported that 2 of 57 patients who underwent this procedure needed additional operations owing to circumferential contracture on the suture line. We consider that the keys to successful repair are avoiding excessively tight suture and trimming the excess inner prepuce based on the appropriate design.

This study has several limitations. The concealed penis group is small and less statistical power to detect differences between success and failure for topical steroid treatment. Therefore accumulation of cases are needed for more accurate evaluation of the possibilities of topical steroid treatment for concealed penis.

\section{Conclusion}

Topical steroid is a simple and easy, noninvasive, and effective treatment for pediatric phimosis. However, the efficacy is very low for concealed penis. Therefore, concealed penis should be corrected surgically for children of 3 years of age and older, if concealment causes poor hygiene, dribbling after voids and psychological burden in pediatric patients.

\section{References}

[1] Kayaba, H., Tamura, H., Kitajima, S., Fujiwara, Y., Kato, T. and Kato, T. (1996) Analysis of Shape and Retractability of the Prepuce in 603 Japanese Boys. Journal of Urology, 156, 1813-1815. http://dx.doi.org/10.1016/S0022-5347(01)65544-7

[2] Gray, R.H., Kigozi, G., Serwadda, D., Makumbi, F., Watya, S., Naluqoda, F., et al. (2007) Male Circumcision for HIV Prevention in Men in Rakai, Uganda. Lancet, 369, 657-666. http://dx.doi.org/10.1016/S0140-6736(07)60313-4

[3] Tobian, A.A., Serwadda, D., Quinn, T.C., Kiqozi, G., Gravitt, P.E., Laeyendecker, O., et al. (2009) Male Circumcision for the Prevention of HSV-2 and HPV Infections and Syphilis. New England Journal of Medicine, 360, 1298-1309. http://dx.doi.org/10.1056/NEJMoa0802556

[4] Esposito, C., Centonze, A., Alicchio, F., Savanelli, A. and Settimi, A. (2008) Topical Steroid Application versus Circumcision in Pediatric Patients with Phimosis: A Prospective Randomized Placebo Controlled Clinical Trial. World Journal of Urology, 26, 187-190. http://dx.doi.org/10.1007/s00345-007-0231-2

[5] Lund, L., Wai, K.H., Mui, L.M. and Yeung, C.K. (2000) Effect of Topical Steroid on Non-Retractile Prepubertal Foreskin by a Prospective, Randomized, Double-Blind Study. Scandinavian Journal of Urology and Nephrology, 34, 267-269. http://dx.doi.org/10.1080/003655900750042013

[6] Palmer, L.S. and Palmer, J.S. (2008) The Efficacy of Topical Betamethasone for Treating Phimosis: A Comparison of Two Treatment Regimens. Urology, 72, 68-71. http://dx.doi.org/10.1016/j.urology.2008.02.030

[7] Radhakrishnan, J., Razzaq, A. and Manickam, K. (2002) Concealed Penis. Pediatric Surgery International, 18, 668-672.

[8] Sugita, Y., Ueoka, K., Tagkagi, S., Hisamatsu, E., Yoshino, K. and Tanikaze, S. (2009) A New Technique of Concealed Penis Repair. Journal of Urology, 182, 1751-1754. http://dx.doi.org/10.1016/j.juro.2009.03.010

[9] Boomers, T.M. and De Jong, T.P.V.M. (1995) The Surgical Correction of Buried Penis: A New Technique. Journal of Urology, 154, 550-552. http://dx.doi.org/10.1016/S0022-5347(01)67108-8

[10] Chu, C.C., Chen, K.C. and Diau, G.Y. (1999) Topical Steroid Treatment of Phimosis in Boys. Journal of Urology, 162, 861-863. http://dx.doi.org/10.1097/00005392-199909010-00078

[11] Webster, T.M. and Leonard, M.P. (2002) Topical Steroid Therapy for Phimosis. Canadian Journal of Urology, 9, 1492-1495.

[12] Maizels, M., Zaontz, M., Donovan, J., Bushnick, P.N. and Firlit, C.F. (1986) Surgical Correction of the Buried Penis: Description of a Classification System and a Technique to Correct the Disorder. Journal of Urology, 136, $268-271$. 
[13] Crawford, B.S. (1977) Buried Penis. British Journal of Plastic Surgery, 30, 96-99. http://dx.doi.org/10.1016/S0007-1226(77)90046-7

[14] Casale, A.J., Beck, S.D., Cain, M.P., Adams, M.C. and Rink, R.C. (1999) Concealed Penis in Childhood: A Spectrum of Etiology and Treatment. Journal of Urology, 162, 1165-1168. http://dx.doi.org/10.1016/S0022-5347(01)68114-X

[15] Frank, T.D. (2000) Editorial Comment. British Journal of Urology International, 86, 526.

[16] Gillett, M.D., Rathbun, S.R., Husmann, D.A., Clay, R.P. and Kramer, S.A. (2005) Split-Thickness Skin Graft for the Management of Concealed Penis. Journal of Urology, 173, 579-582. http://dx.doi.org/10.1097/01.ju.0000149606.27158.fa

[17] Zampieri, N., Corroppolo, M., Camoglio, F.S., Giacomello, L. and Ottolenghi, A. (2005) Phimosis: Stretching Methods with or without Application of Topical Steroids? Journal of Pediatrics, 147, 705-706. http://dx.doi.org/10.1016/j.jpeds.2005.07.017 